\title{
GMR
}

\section{Role of ERCC2 and ERCC3 gene polymorphisms in the development of osteosarcoma}

\author{
X. Ma, Y. Zhang, T.S. Sun and J.H. Yao \\ Department of Orthopedics, Chinese PLA Medical Academy, Beijing, China \\ Corresponding author: T.S. Sun \\ E-mail: suntsts@126.com \\ Genet. Mol. Res. 15 (1): gmr.15017302 \\ Received July 24, 2015 \\ Accepted October 26, 2015 \\ Published March 31, 2016 \\ DOI http://dx.doi.org/10.4238/gmr.15017302
}

\begin{abstract}
We conducted a case-control study to investigate the role of common SNPs in ERCC2 (rs13181 and rs1799793) and ERCC3 (rs4150441 and rs4150506) in the development of osteosarcoma. A 1:2 matched case-control study was conducted. Between January 2012 and December 2013, 141 patients with pathologically diagnosed osteosarcoma and 282 controls were recruited in our study. Genotyping of ERCC2 rs13181 and rs1799793 as well as ERCC3 rs4150441 and rs4150506 were performed using polymerase chain reaction coupled with restriction fragment length polymorphism. The genotype distributions of ERCC2 rs13181 and rs1799793 as well as ERCC3 rs4150441 and rs4150506 showed no significant difference between patients with osteosarcoma and controls, as analyzed by $\chi^{2}$ tests. Multivariate logistic regression analysis did not reveal significant associations between ERCC2 rs 13181/rs1799793 or ERCC3 rs4150441/ rs4150506 gene polymorphisms and the development of osteosarcoma in codominant, dominant, and recessive models. In conclusion, we did not find any association between ERCC2 or ERCC3 gene polymorphisms and the development of osteosarcoma. Future studies with larger sample sizes may contribute in elucidating the impact of ERCC2 and ERCC3 gene polymorphisms on osteosarcoma risks.
\end{abstract}

Key words: ERCC2; ERCC3; Polymorphism; Osteosarcoma 


\section{INTRODUCTION}

Osteosarcoma is a highly malignant and aggressive bone tumor derived from mesenchymal tissues, and often occurs in the distal femur, proximal tibia, and humeral metaphysis. Osteosarcoma generally occurs in individuals between 10 and 30 years of age (Mirabello et al., 2009). It is estimated that the annual incidence of osteosarcoma is about 3 in 10,000 (Mirabello et al., 2009). It is well known that the development of osteosarcoma is a complex, multi-step and multi-factorial process, and is caused by a combination of environmental and genetic factors (Bovée and Hogendoorn, 2010; Powers et al., 2010). Several studies have investigated the potential of cancer stem cells to cause tumors (Berger et al., 2008; Osuna and de Alava, 2009). The concept that genetic factors are involved in the susceptibility to osteosarcoma has gained popularity in the last decade, and many studies were conducted to investigate the genetic determinants of osteosarcoma.

In normal cells, DNA is continually subjected to a variety of endogenous and exogenous sources of damage. Therefore, efficient DNA repair is vital for the repair of errors and maintenance of genomic stability. The nucleotide excision repair (NER) pathway is an important DNA repair process involved in maintaining genome integrity. ERCC3/XPB and ERCC2/XPD are two important proteins in the NER pathway, and function as ATP-dependent DNA helicases. They act by opening the DNA strand around the lesion site to remove certain DNA crosslinks, UV photolesions, and bulky chemical adducts (Weeda et al., 1990; Batty and Wood, 2000). To date, only one study has reported the role of ERCC2 gene polymorphisms in the development of osteosarcoma (Jin et al., 2015). Therefore, we conducted a case-control study to investigate the role of common SNPs in ERCC2 (rs13181 and rs1799793) and ERCC3 (rs4150441 and rs4150506) in the development of osteosarcoma.

\section{MATERIAL AND METHODS}

\section{Study population}

Between January 2012 and December 2013, 158 patients with pathologically diagnosed osteosarcoma were recruited. Patients who had primary tumors other than osteosarcoma, tumors of unknown origins, or any histopathological diagnosis other than osteosarcoma were excluded from the study. In total, 141 patients with osteosarcoma were included into our study; participation rate was $89.24 \%$.

Healthy adult subjects (282) without osteosarcoma were randomly recruited from individuals who came to receive regular health check-up at our hospital during the same period. Each osteosarcoma patient was matched to two controls based on gender and age ( \pm 5 years).

The demographic and clinical information regarding patients with osteosarcoma and controls were obtained from self-designed questionnaires and medical records, and include information such as gender, age, family history of cancer, Enneking stage, tumor location, and tumor metastasis. Signed written informed consents were obtained from all subjects enrolled in the study. The study protocol was approved by the Ethics Committee of the Liberation Army Medical College.

\section{Genotyping}

Peripheral blood sample $(2 \mathrm{~mL})$ was drawn from all subjects, and was stored at $-80^{\circ} \mathrm{C}$ until use. Genotyping of ERCC2 rs13181 and rs1799793 as well as ERCC3 rs4150441 and 
rs4150506 were analyzed using polymerase chain reaction coupled with restriction fragment length polymorphism. Primer sequences for ERCC2 rs13181 and rs1799793, and ERCC3 rs4150441 and rs41505061 polymorphisms were designed using the Primer premier v5.0 software (PREMIER Biosoft. Ltd., Palo Alto, CA, USA). Amplification conditions were as follows: $95^{\circ} \mathrm{C}$ for $5 \mathrm{~min}$, then 30 cycles of $94^{\circ} \mathrm{C}$ for $0.5 \mathrm{~min}, 60^{\circ} \mathrm{C}$ for $0.5 \mathrm{~min}$, and $72^{\circ} \mathrm{C}$ for $1 \mathrm{~min}$, followed by $72^{\circ} \mathrm{C}$ for $10 \mathrm{~min}$. The resulting DNA fragments were stained with ethidium bromide, ran on a $3.5 \%$ agarose gel, and visualized under UV light.

\section{Statistical analysis}

Differences in demographic and clinical characteristics between patients with osteosarcoma and controls were analyzed by chi-squared tests. Deviation from Hardy-Weinberg equilibrium of ERCC2 rs13181 and rs1799793 as well as ERCC3 rs4150441 and rs4150506 in controls were evaluated by the Fisher exact tests. Chi-squared tests were used to calculate the differences in genotype distribution between patients with osteosarcoma and controls. The odds ratios and $95 \%$ confidence intervals were evaluated for the association between each gene polymorphism and the risk of osteosarcoma; logistic regression models were adjusted for confounding factors. A P value was considered significant at a level of $<0.05$. The Statistical Analyses System (SAS) package (version 8.01; SAS Institute, Cary, NC, USA) was used for statistical analysis.

\section{RESULTS}

The demographic and clinical characteristics of patients with osteosarcoma and controls are shown in Table 1. As subjects were matched by gender and age, no significant differences were found between patient with osteosarcoma and controls in terms of gender and age. However, we found that patients were more likely to have a family history of osteosarcoma in the first relatives when compared with controls. Of the 141 patients, $76(53.90 \%)$ were at I-II Enneking stage, 96 (68.09\%) showed tumor location at extremities, and 51 (36.17\%) showed positive tumor metastasis.

\begin{tabular}{|c|c|c|c|c|c|c|}
\hline Variables & Patients & $\%$ & Controls & $\%$ & $\chi^{2}$ value & $\mathrm{P}$ value \\
\hline \multicolumn{7}{|l|}{ Gender } \\
\hline Females & 54 & 38.30 & 108 & 38.30 & & \\
\hline Males & 87 & 61.70 & 174 & 61.70 & 0.00 & 1.00 \\
\hline \multicolumn{7}{|l|}{ Age, years } \\
\hline$<20$ & 88 & 62.41 & 162 & 57.45 & & \\
\hline$>20$ & 53 & 37.59 & 120 & 42.55 & 0.96 & 0.33 \\
\hline \multicolumn{7}{|c|}{ Family history of cancer } \\
\hline No & 137 & 97.16 & 282 & 100.00 & & \\
\hline Yes & 4 & 2.84 & 0 & 0.00 & 8.08 & 0.012 \\
\hline \multicolumn{7}{|c|}{ Enneking stage } \\
\hline I-II & 76 & 53.90 & & & & \\
\hline III & 65 & 46.10 & & & & \\
\hline \multicolumn{7}{|c|}{ Tumor location } \\
\hline Extremities & 96 & 68.09 & & & & \\
\hline Other & 45 & 31.91 & & & & \\
\hline \multicolumn{7}{|c|}{ Tumor metastasis } \\
\hline Negative & 90 & 63.83 & & & & \\
\hline Positive & 51 & 36.17 & & & & \\
\hline
\end{tabular}


The genotype distributions of ERCC2 rs13181 and rs1799793 as well as ERCC3 rs4150441 and rs4150506 are listed in Table 2. By the Fisher exact test, we found that genotype distributions of ERCC2 rs1799793, ERCC3 rs4150441, and ERCC3 rs4150506 were in line with Hardy-Weinberg equilibrium (HWE), but not ERCC2 rs13181 (Table 2). The genotype distributions of ERCC2 rs13181, ERCC2 rs1799793, ERCC3 rs4150441, and ERCC3 rs4150506 showed no significant difference between osteosarcoma patients and controls, as analyzed by $\chi^{2}$ tests. Multivariate logistic regression analysis revealed no significant association between any of the gene polymorphisms and the development of osteosarcoma in codominant, dominant, and recessive models.

\begin{tabular}{|c|c|c|c|c|c|c|c|c|c|}
\hline \multirow{2}{*}{\multicolumn{10}{|c|}{ ERCC2 rs13181 }} \\
\hline & & & & & & & & & \\
\hline \multicolumn{10}{|c|}{ Codominant } \\
\hline TT & 96 & 68.09 & 206 & 73.05 & & & & 1.0 (Ref.) & - \\
\hline TG & 32 & 22.70 & 58 & 20.57 & & & & $1.18(0.70-2.00)$ & 0.5 \\
\hline GG & 13 & 9.22 & 18 & 6.38 & 1.56 & 0.46 & $<0.001$ & $1.55(0.67-3.50)$ & 0.25 \\
\hline \multicolumn{10}{|l|}{ Dominant } \\
\hline TT & 96 & 68.09 & 206 & 73.05 & & & & 1.0 (Ref.) & - \\
\hline$T G+G G$ & 45 & 31.92 & 76 & 26.95 & 1.13 & 0.29 & & $1.27(0.80-2.02)$ & 0.29 \\
\hline \multicolumn{10}{|l|}{ Recessive } \\
\hline$T T+T G$ & 128 & 90.79 & 264 & 93.62 & & & & 1.0 (Ref.) & - \\
\hline GG & 13 & 9.22 & 18 & 6.38 & 1.11 & 0.29 & & $1.49(0.65-3.32)$ & 0.29 \\
\hline \multicolumn{10}{|c|}{ ERCC2 rs 1799793} \\
\hline \multicolumn{10}{|c|}{ Codominant } \\
\hline AA & 60 & 42.55 & 134 & 47.52 & & & & 1.0 (Ref.) & - \\
\hline $\mathrm{AG}$ & 62 & 43.97 & 117 & 41.49 & & & & $1.18(0.75-1.87)$ & 0.45 \\
\hline GG & 19 & 13.48 & 31 & 10.99 & 1.13 & 0.57 & 0.48 & $1.37(0.67-2.73)$ & 0.34 \\
\hline \multicolumn{10}{|l|}{ Dominant } \\
\hline $\mathrm{AA}$ & 60 & 42.55 & 134 & 47.52 & & & & 1.0 (Ref.) & - \\
\hline$A G+G G$ & 81 & 57.45 & 148 & 52.48 & 0.93 & 0.33 & & $1.22(0.80-1.88)$ & 0.33 \\
\hline \multicolumn{10}{|c|}{ Recessive } \\
\hline$A A+A G$ & 122 & 86.52 & 251 & 89.01 & & & & 1.0 (Ref.) & - \\
\hline GG & 19 & 13.48 & 31 & 10.99 & 0.56 & 0.46 & & $1.26(0.64-2.41)$ & 0.46 \\
\hline \multicolumn{10}{|c|}{ ERCC3 rs 4150441} \\
\hline \multicolumn{10}{|c|}{ Codominant } \\
\hline GG & 56 & 39.72 & 123 & 43.62 & & & & 1.0 (Ref.) & - \\
\hline GA & 66 & 46.81 & 129 & 45.74 & & & & $1.12(0.71-1.78)$ & 0.6 \\
\hline AA & 19 & 13.48 & 30 & 10.64 & 1.01 & 0.6 & 0.66 & $1.39(0.68-2.80)$ & 0.32 \\
\hline \multicolumn{10}{|l|}{ Dominant } \\
\hline GG & 56 & 39.72 & 123 & 43.62 & & & & 1.0 (Ref.) & - \\
\hline $\mathrm{GA}+\mathrm{AA}$ & 85 & 60.29 & 159 & 56.38 & 0.59 & 0.44 & & $1.17(0.76-1.81)$ & 0.44 \\
\hline \multicolumn{10}{|l|}{ Recessive } \\
\hline$G G+G A$ & 122 & 86.53 & 252 & 89.36 & & & & 1.0 (Ref.) & - \\
\hline $\mathrm{AA}$ & 19 & 13.48 & 30 & 10.64 & 26.17 & $<0.001$ & & $1.31(0.67-2.51)$ & 0.39 \\
\hline \multicolumn{10}{|c|}{ ERCC3 rs4150506 } \\
\hline \multicolumn{10}{|c|}{ Codominant } \\
\hline $\mathrm{CC}$ & 65 & 46.10 & 148 & 52.48 & & & & 1.0 (Ref.) & - \\
\hline CT & 59 & 41.84 & 109 & 38.65 & & & & $1.23(0.78-1.94)$ & 0.34 \\
\hline TT & 17 & 12.06 & 26 & 9.22 & 1.75 & 0.42 & 0.37 & $1.49(0.71-3.07)$ & 0.25 \\
\hline \multicolumn{10}{|l|}{ Dominant } \\
\hline $\mathrm{CC}$ & 65 & 46.1 & 148 & 52.48 & & & & 1.0 (Ref.) & - \\
\hline & 76 & 53.9 & 135 & 47.87 & 1.45 & 0.23 & & $1.28(0.84-1.96)$ & 0.23 \\
\hline \multicolumn{10}{|l|}{ Recessive } \\
\hline $\mathrm{CC}+\mathrm{CT}$ & 124 & 87.94 & 257 & 91.13 & & & & 1.0 (Ref.) & - \\
\hline TT & 17 & 12.06 & 26 & 9.22 & 0.85 & 0.36 & & $1.36(0.66-2.70)$ & 0.36 \\
\hline
\end{tabular}

\section{DISCUSSION}

To the best of our knowledge, this is the first report, which investigates the impact of ERCC3 and ERCC2 gene polymorphisms on osteosarcoma susceptibility in the Chinese population. In our study, we did not find any association between ERCC2 and ERCC3 gene polymorphisms and the risk of osteosarcoma.

Many previous epidemiologic studies have been conducted to examine the association between ERCC2 and ERCC3 gene polymorphisms and risk of cancers, such as lung, endometrial, head and neck, and laryngeal cancer (Hu et al., 2006; Doherty et al., 2011; Sakoda et al., 2012; Khlifi et al., 2014; Lu et al., 2014). Hu et al. (2006) conducted a case-control study in a Chinese population, 
and found that ERCC2 and ERCC3 gene polymorphisms contribute to the development of lung cancer. Doherty et al. (2011) conducted a case-control study to investigate the association between 64 SNPs in NER genes and the risk of endometrial cancer in a Chinese population. It was found that ERCC2 and ERCC3 gene polymorphisms do not contribute to the development of this type of cancer. Khlifi et al. (2014) investigated the role of ERCC2 and ERCC3 gene polymorphisms on susceptibility to head and neck cancer, and they observed no statistically significant association between the risk of head and neck cancers and the two gene polymorphisms. Lu et al. (2014) conducted a case-control study in a Chinese population, and suggested that ERCC2 and ERCC3 polymorphisms contribute to the development of laryngeal cancer. Only one study reported an association between ERCC2 and ERCC3 gene polymorphisms and the development of osteosarcoma (Jin et al., 2015). Jin et al. (2015) reported that ERCC2 rs1799793 was associated with an increased risk of osteosarcoma. However, we did not find any association between the tested ERCC2 or ERCC3 SNPs and the risk of osteosarcoma. The discrepancies in these results may be due to differences in cancer type, study design, sample size, and selection of patients and controls.

There are several limitations in our study. First, patients and controls were selected from a single hospital, which may cause selection bias in this study. Second, the sample size of patients with osteosarcoma was relatively small, which may have limited statistical power in our study, and may be the reason why we did not find significant association between gene polymorphisms and the risk of osteosarcoma. Third, it is clear that genetic susceptibility to cancer is composed of complex interactions between genetic and environmental factors. However, we were unable to assess gene-environment interactions due to insufficient data in this study. Therefore, validation of association in other population is required for further studies.

In conclusion, we did not find any association between ERCC2 and ERCC3 gene polymorphisms and the development of osteosarcoma. Future studies with larger sample sizes may help elucidate the impact of ERCC2 and ERCC3 gene polymorphisms on the risk of osteosarcoma.

\section{Conflicts of interest}

The authors declare no conflict of interest.

\section{REFERENCES}

Batty DP and Wood RD (2000). Damage recognition in nucleotide excision repair of DNA. Gene 241: 193-204. http://dx.doi. org/10.1016/S0378-1119(99)00489-8

Berger M, Muraro M, Fagioli F and Ferrari S (2008). Osteosarcoma derived from donor stem cells carrying the norrie's disease gene. N. Engl. J. Med. 359: 2502-2504. http://dx.doi.org/10.1056/NEJMc0807172

Bovée JV and Hogendoorn PC (2010). Molecular pathology of sarcomas: Concepts and clinical implications. Virchows Arch. 456: 193-199. http://dx.doi.org/10.1007/s00428-009-0828-5

Doherty JA, Weiss NS, Fish S, Fan W, et al. (2011). Polymorphisms in nucleotide excision repair genes and endometrial cancer risk. Cancer Epidemiol. Biomarkers Prev. 20: 1873-1882. http://dx.doi.org/10.1158/1055-9965.EPI-11-0119

Hu Z, Xu L, Shao M, Yuan J, et al. (2006). Polymorphisms in the two helicases ERCC2/XPD and ERCC3/XPB of the transcription factor IIH complex and risk of lung cancer: a case-control analysis in a Chinese population. Cancer Epidemiol. Biomarkers Prev. 15: 1336-1340. http://dx.doi.org/10.1158/1055-9965.EPI-06-0194

Jin G, Wang M, Chen W, Shi W, et al. (2015). Single nucleotide polymorphisms of nucleotide excision repair and homologous recombination repair pathways and their role in the risk of osteosarcoma. Pak. J. Med. Sci. 31: 269-273.

Khlifi R, Kallel I, Hammami B, Hamza-Chaffai A, et al. (2014). DNA repair gene polymorphisms and risk of head and neck cancer in the Tunisian population. J. Oral Pathol. Med. 43: 217-224. http://dx.doi.org/10.1111/jop.12114

Lu B, Li J, Gao Q, Yu W, et al. (2014). Laryngeal cancer risk and common single nucleotide polymorphisms in nucleotide 
excision repair pathway genes ERCC1, ERCC2, ERCC3, ERCC4, ERCC5 and XPA. Gene 542: 64-68. http://dx.doi. org/10.1016/j.gene.2014.02.043

Mirabello L, Troisi RJ and Savage SA (2009). Osteosarcoma incidence and survival rates from 1973 to 2004: data from the Surveillance, Epidemiology, and End Results Program. Cancer 115: 1531-1543. http://dx.doi.org/10.1002/cncr.24121

Osuna D and de Alava E (2009). Molecular pathology of sarcomas. Rev. Recent Clin. Trials. 4: 12-26. http://dx.doi. org/10.2174/157488709787047585

Powers M, Zhang W, Lopez-Terrada D, Czerniak BA, et al. (2010). The molecular pathology of sarcomas. Cancer Biomarkers 9: $475-491$.

Sakoda LC, Loomis MM, Doherty JA, Julianto L, et al. (2012). Germ line variation in nucleotide excision repair genes and lung cancer risk in smokers. Int. J. Mol. Epidemiol. Genet. 3: 1-17.

Weeda G, van Ham RC, Vermeulen W, Bootsma D, et al. (1990). A presumed DNA helicase encoded by ERCC-3 is involved in the human repair disorders Xeroderma pigmentosum and Cockayne's syndrome. Cell 62: 777-791. http://dx.doi. org/10.1016/0092-8674(90)90122-U 